\title{
Effect of Welding Time on Strength of Friction Stir Spot Welded Aluminum Alloy/Acrylic Plastic Joint
}

\author{
Mitsuhiro Watanabe ${ }^{1}$, Masaya Kato ${ }^{2}$, Yu Noguchi $^{3}$, Etsuhiro Tsukidate ${ }^{3}$, Kazunori Yoshida ${ }^{3}$ \\ ${ }^{1}$ Department of Precision Machinery Engineering, College of Science and Technology, Nihon University, \\ 7-24-1 Narashinodai, Funabashi-shi, Chiba 274-8501, Japan \\ watanabe.mitsuhiro@nihon-u.ac.jp \\ ${ }^{2}$ Graduate student, Department of Precision Machinery Engineering, \\ Graduate School of Science and Technology, Nihon University, \\ 7-24-1 Narashinodai, Funabashi-shi, Chiba 274-8501, Japan \\ csma20017@g.nihon-u.ac.jp \\ ${ }^{3}$ Machining Technology Center, College of Science and Technology, Nihon University, \\ 7-24-1 Narashinodai, Funabashi-shi, Chiba 274-8501, Japan \\ noguchi.yuu@nihon-u.ac.jp; tsukidate.etsuhiro@nihon-u.ac.jp; yoshida.kazunori@nihon-u.ac.jp
}

\begin{abstract}
Dissimilar material lap welding of A5052 aluminum alloy and polymethylmethacrylate acrylic plastic plates was performed by using friction stir spot welding. A columnar welding tool was made of SKH51 high-speed tool steel and was composed of a shoulder part and a probe part. The aluminum plate was overlapped on the acrylic plastic plate, and the welding tool was plunged from the aluminum alloy plate. The dwell time at the plunged depth and the welding time from contact of the welding tool and surface of the aluminum alloy to drawing of the welding tool from the joint were controlled. The joint strength was evaluated by using tensile-shear test. Microstructural observation was performed using stereoscopic microscope and optical microscope. The welding was achieved at the dwell time from $0 \mathrm{~s}$ to $3 \mathrm{~s}$ and at the welding time from $2.2 \mathrm{~s}$ to $9.3 \mathrm{~s}$. A circular welded zone was formed at the aluminum/acrylic plastic interface corresponded to the area where the welding tool was plunged, and the area of the welded zone increased with increasing the dwell time of the welding time. The tensile-shear test of the joints showed that a higher joint strength is obtained in the joints welded at the welding time of $4 \mathrm{~s}$ or less regardless of any dwell time. Discontinuous micrometer sized voids were observed in the joints welded at the welding time of $4 \mathrm{~s}$ or less, whereas continuous millimeter sized voids were formed at the welding interface in the joints welded at the welding time longer than $4 \mathrm{~s}$. The formation of the coarse voids at the welding interface is assumed to result in decreasing the joint strength of the aluminum/acrylic plastic lap joint.
\end{abstract}

Keywords: friction stir spot welding, aluminum, polymethylmethacrylate acrylic plastic, joint strength, welding interface

\section{Introduction}

Dissimilar material welding is one of the important technology which is desired for increasing the functionality of equipment [1]. In particular, welding of metal and plastic is demanded for weight saving of automobile. Aluminum alloy is attracting attention as a metal for reducing the weight of automobile, because it has low density and high strength. Since fiber reinforced plastic (FRP) has high strength and light weight, its application to automobile is desired. The FRP is reinforced by impregnating the plastic with fibers, and the surface is almost covered with the plastic. Namely, for the welding of them, a welding technique of aluminum and plastic is required.

Friction stir spot welding is a method which applied friction stir welding to spot welding [2]. Figure 1 shows schematic illustration of friction stir spot welding method. The welding is achieved by the plastic flow which is induced by inserted high-speed rotating welding tool and friction heat generated between plate surface and the rotating tool. It is well-known that this welding method results in the welding of aluminum at solid state [3]. Namely, this welding method can perform at relatively low temperature, whereas it is unclear whether solid-state welding of plastic will be achieved because melting temperature of plastic is lower than that of aluminum. In this study, we investigated effect of welding time, which is one of the welding parameter related to heat input to the welding interface, on strength and microstructure of the aluminum alloy/plastic joint. 


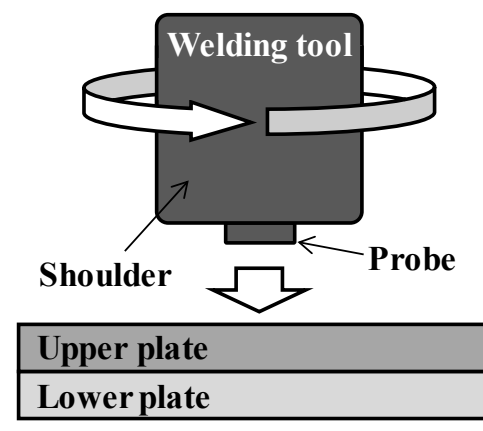

\section{Experimental Procedure}

\subsection{Materials}

A $2.0 \mathrm{~mm}$ thick A5052 aluminum alloy (hereafter Al alloy) plate and a $3 \mathrm{~mm}$ thick polymethylmethacrylate acrylic plastic (hereafter PMMA) plate were used as the welding materials in this study. The plate length and width were $100 \mathrm{~mm}$ and $30 \mathrm{~mm}$, respectively. Before the welding, the surface of Al alloy plate was mechanically polished using \#1000 waterproof abrasive paper. After the surface polishing, the Al plate was ultrasonically cleaned in acetone and dried well.

The welding tool was made of SKH51 high-speed tool steel, and was composed of a columnar shoulder and probe. The shoulder diameter, the probe diameter, and the probe length were $8.0 \mathrm{~mm}, 3.0 \mathrm{~mm}$, and $1.0 \mathrm{~mm}$, respectively.

\subsection{Welding condition}

Friction stir spot welding was performed by using a vertical-type milling machine. The PMMA plate was placed in a cast steel table and the Al alloy plate was fixed on the PMMA plate. The high-speed rotating welding tool was plunged into the Al alloy plate. The rotational speed and the plunge depth of the welding tool was fixed at $1375 \mathrm{rpm}$ and $1.1 \mathrm{~mm}$, respectively. In this study, the welding time and the dwell time of the welding tool were changed. Figure 2 shows the definition of the welding time and the dwell time in the welding process. The welding time was defined as the time from when the tip of the tool came into contact with the surface of the Al alloy plate until it was pulled out from the joint. The dwell time was the time that the tool stays at the predetermined plunge depth. The welding time and the dwell time were changed from $2 \mathrm{~s}$ to $10 \mathrm{~s}$ and from $0 \mathrm{~s}$ to $3 \mathrm{~s}$, respectively.

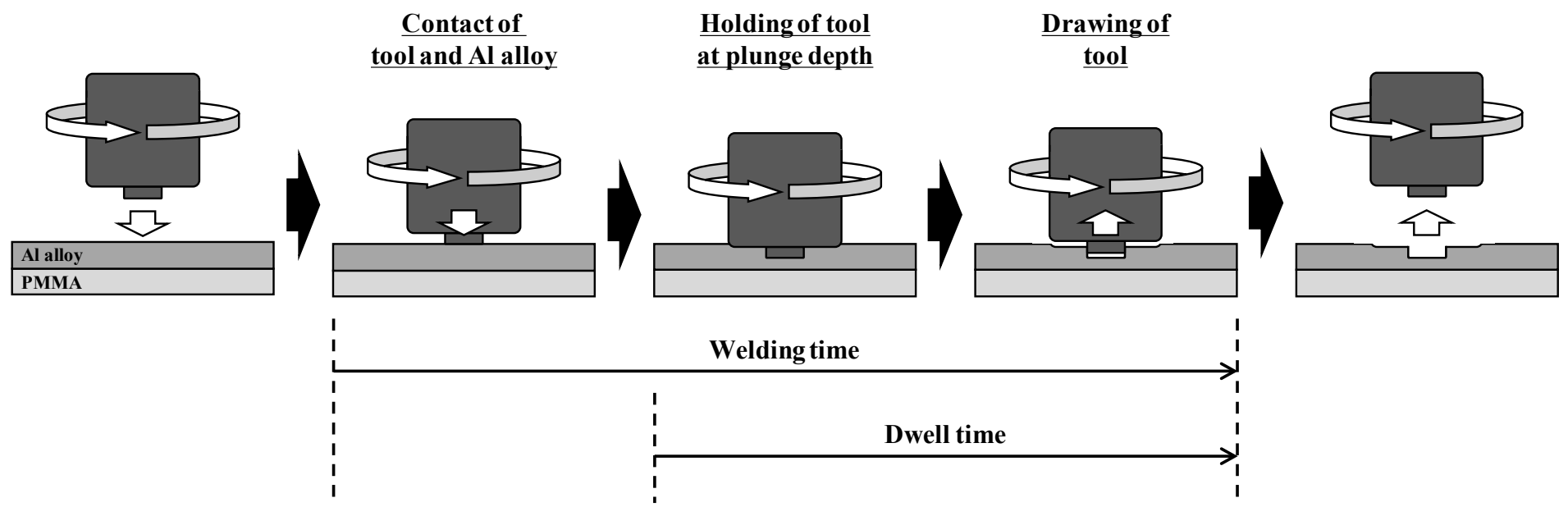

Fig. 2: Definition of welding time and dwell time. 


\subsection{Evaluation of Joint Strength and Observation of Joint}

Joint strength was evaluated by tensile-shear test. The tensile-shear test was performed with tensile speed of 0.25 $\mathrm{mm} / \mathrm{min}$ at room temperature.

The obtained joint was examined by using a stereoscopic microscope and an optical microscope. The joint was observed from PMMA side and cross section direction. For the cross-sectional observation, the cross section of the joint was mechanically polished using waterproof abrasive papers.

\section{Results and discussion}

\subsection{Appearance of friction stir spot welded Al alloy/PMMA joint and its welding interface}

Figure 3(a) shows entire of friction stir spot welded Al alloy/PMMA joint. No strain was observed in the joint. The trace of the welding tool being plunged in was formed on the surface of the $\mathrm{Al}$ alloy. The tool plunging area observed from (b) the Al alloy side, (c) the PMMA side, and (d) the cross-sectional direction were shown in Fig. 3. Shape of tip of the welding tool was clearly transferred to the surface of the Al alloy plate. There were few burrs on the surface of the Al alloy plate. The back surface of the Al alloy plate was deformed in the direction of the PMMA plate. The deformation was the largest at the center which corresponded to the center of the welding tool, and became smaller toward the outside. In addition, a circular melt zone of PMMA was formed around the deformed area at the interface of the Al alloy plate and the PMMA plate. The area of the formed circular melt zone increased with increasing both of the welding time and the dwell time (Fig. 4). The range of the circular melt zone corresponded to the welded zone, indicating that the welding occurred between solid $\mathrm{Al}$ and melted PMMA.

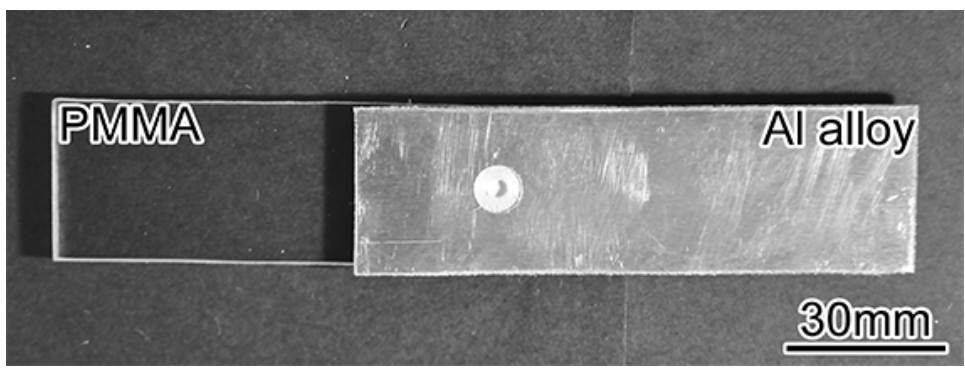

(a)

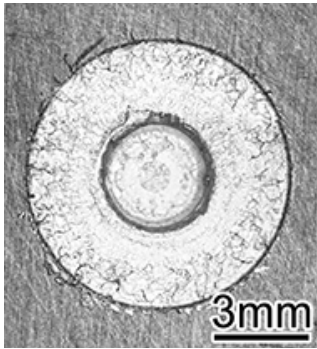

(b)

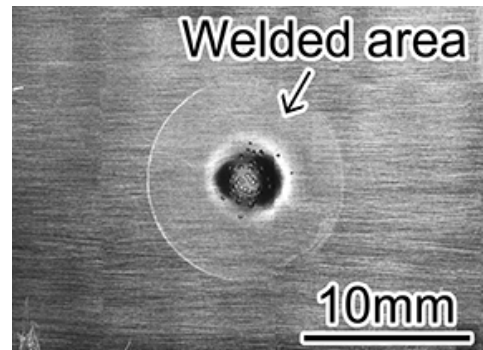

(c)

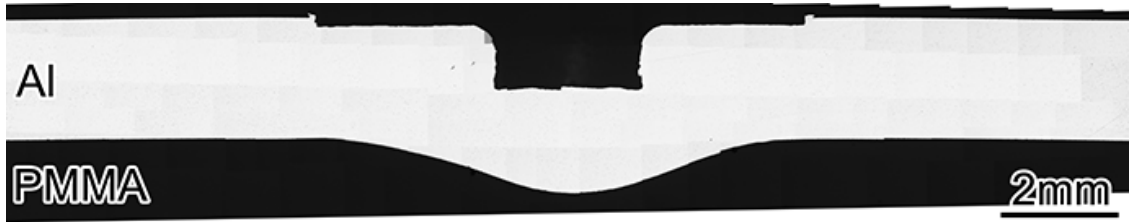

(d)

Fig. 3: (a) Appearance of joint. (b) Welded zone (Al side). (c) Welded zone (PMMA side). (d) Cross-sectional image of joint. 


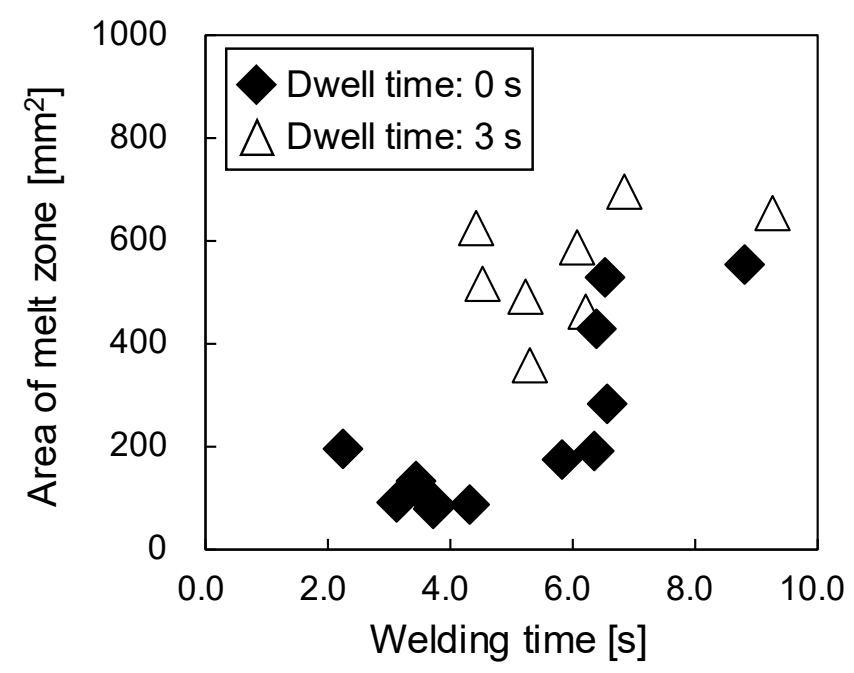

Fig. 4: Relationship among welding time, dwell time and area of melt zone.

\subsection{Effect of Welding Time on Joint Strength and Welding Interface}

Figure 5 shows relationship among the welding time, dwell time and fracture stress. The fracture by the test occurred at the welding interface. The fracture stress was estimated by dividing the fracture load obtained by tensile-shear test by circular welded zone. The fracture stress of the joints welded at the dwell time of $0 \mathrm{~s}$ was higher than that of the joints welded at the dwell time of $3 \mathrm{~s}$. Also, in case of the fixed dwell time of $0 \mathrm{~s}$, although the joints welded at the welding time of $4 \mathrm{~s}$ or less showed higher fracture stress, the joint welded at the welding time longer than $4 \mathrm{~s}$ showed lower fracture stress.

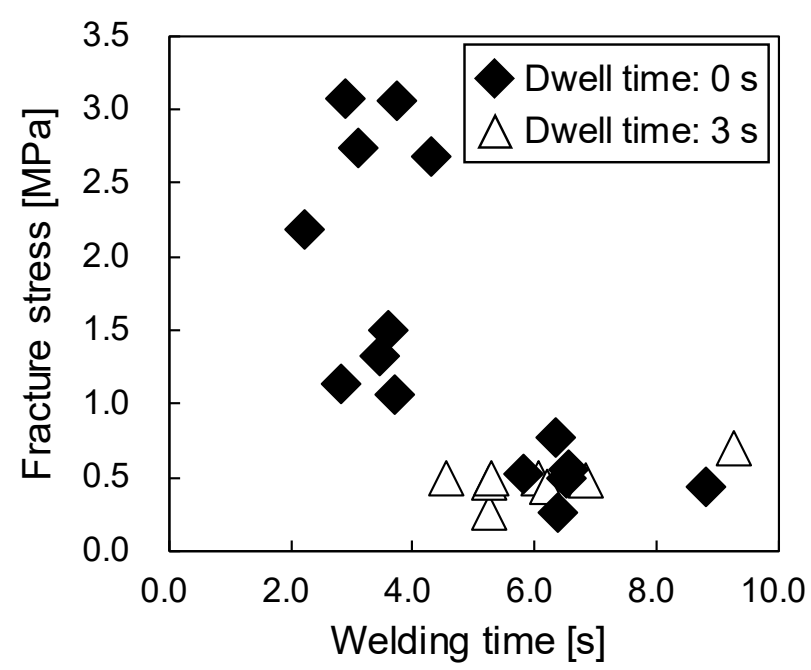

Fig. 5: Relationship among welding time, dwell time and fracture stress.

Figure 6 shows optical micrographs of the joints welded at the dwell time of (a) $0 \mathrm{~s}$ (welding time: $3.6 \mathrm{~s}$ ) and (b) $3 \mathrm{~s}$ (welding time: $6.2 \mathrm{~s}$ ). The circular welded zone was formed in all joints and its diameter increased with increasing the dwell time. Some voids were observed at the welding interface which corresponded to the position where the welding tool was plunged, and its largeness was different by the dwell time. Discontinuous micrometer sized voids were observed in the joint welded at the dwell time of $0 \mathrm{~s}$ (Fig. 6(a)). On the other hand, in the joint welded at the dwell time of $3 \mathrm{~s}$, several millimeter 
sized voids were formed (Fig. 6(b)). Figure 6(c) shows optical micrograph of the joints welded at the dwell time of $0 \mathrm{~s}$ and at the welding time of $6.3 \mathrm{~s}$. The formation of the millimeter sized voids was observed at the joints welded at the welding time longer than $4 \mathrm{~s}$ (Fig. 6(c)), and some micrometer sized voids were observed at the joints welded art the welding time of $4 \mathrm{~s}$ or less (Fig. 6(a)).

Growth of the void was observed at the welding interface in the joints welded at the longer welding time regardless of any dwell time. This indicates that the heat input to the Al alloy/PMMA interface involves not only the friction heat generated at the plunge depth but also the friction heat generated during the plunging of the welding tool and the heat generated by plastic deformation. Also, the joints in which the millimeter sized voids were formed showed lower joint strength. This is assumed to indicate that the coarse void formed at the welding interface acted as the origin of fracture.

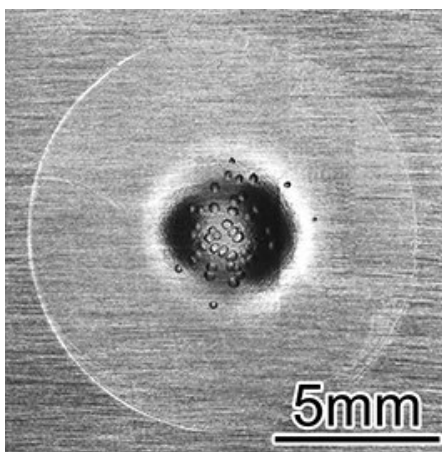

(a)

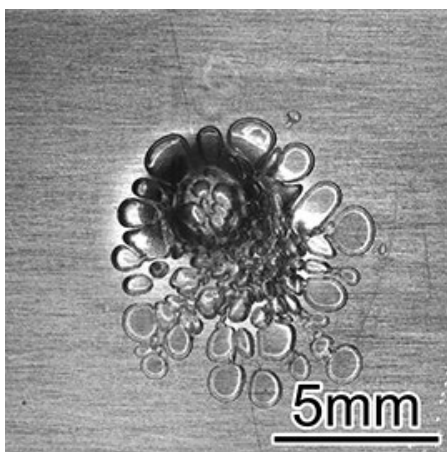

(b)

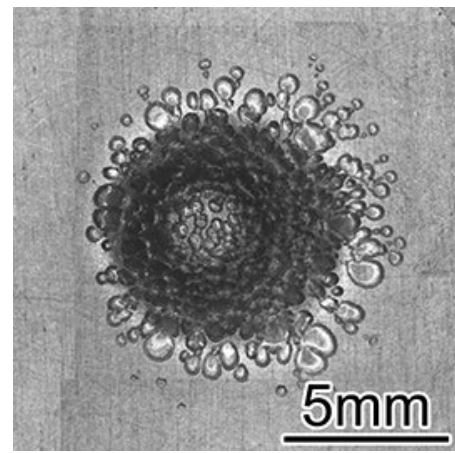

(c)

Fig. 6: Voids at welding interface. (a) Dwell time of $0 \mathrm{~s}$ and welding time of $3.6 \mathrm{~s}$.

(b) Dwell time of $3 \mathrm{~s}$ and welding time of $6.2 \mathrm{~s}$. (c) Dwell time of $0 \mathrm{~s}$ and welding time of $6.3 \mathrm{~s}$.

\section{Conclusion}

Friction stir spot lap welding of A5052 aluminum alloy and polymethylmethacrylate acrylic plastic was performed by changing the dwell time and the welding time. The welding was achieved at the dwell time from $0 \mathrm{~s}$ to $3 \mathrm{~s}$ and at the welding time from $2.2 \mathrm{~s}$ to $9.3 \mathrm{~s}$. A circular welded zone was formed and its area increased with increasing the dwell time and the welding time. Higher joint strength was obtained in the joints welded at the shorter welding time regardless of any dwell time. When the joints were fabricated at longer welding time, millimeter sized coarse voids were formed at the welding interface. The formation of coarse voids at the welding interface is considered to result in decreasing the joint strength.

\section{References}

[1] Y. Sugimoto, "Multi Material Car Body and Dissimilar Material Joining Technologies", vol. 87, no. 1, pp. 66-70, 2018.

[2] Z. Shen, Y. Ding and A.P. Gerlich, "Advances in friction stir spot welding”, vol. 45, no. 6, pp. 457-534, 2020.

[3] Q. Yang, S. Mironov, Y.S. Sato and K. Okamoto, "Material flow during friction stir spot welding", vol. 527, no. 16-17, pp. 4389-4398, 2010. 